Eur Surg (2019) 51:1-4

https://doi.org/10.1007/s10353-018-0566-5

CrossMark

\section{Far-out surgery of the future}

\author{
Martin Riegler
}

Published online: 4 January 2019

(C) Springer-Verlag GmbH Austria, part of Springer Nature 2019

Dear reader,

Welcome to this issue of European Surgery. The highly motivated team of authors has orchestrated a large spectrum of topics, studies, and contributions of relevance, actuality, and importance for the daily routine of academic surgery, science, and reasoning. May the papers help you to improve interdisciplinary disease management.

In the recent issues of European Surgery we found that myth and disease management share comparable ideas, qualities, and characteristics. As such, myth and medicine aim to translate images into treatable signs. Myth and clinical science aim to foster a better understanding of the genesis of perceptions, diseases, and their manifestations, i.e., the symptoms. Therefore, we also examined the mechanisms of perceptions and the interactions between perceptions, atmosphere, and the processing of information. Finally, we came up with the notion that the amazing essence of our stream of existence follows the unbelievable atmospheric character of being borrowed (Figs. 1 and 2). This understanding should not be taken for granted and thus claims for humility, passion, and gratitude. In contrast to this evolves the will for power, altruism, and freedom.

Academic science represents the modern and most fascinating part of the myth of mankind. Clinical trials replace story telling. Thanks to the enthusiasm of thousands of scientists, we gain a better understanding of the world, the micro- and macrocosmos. Daily reports improve our knowledge and motivate us to continue our search for the truth. As such, scientist recently discovered, i. e., brought into our perception,

Doz. Dr. M. Riegler $(\bowtie)$

Reflux Medical, Mariannengasse 10/9, 1090 Vienna, Austria martin.riegler@refluxmedical.com european surgery the "Farout" 500-km-diameter pink powered planet at the edge of our solar system. The implementation of new data into our daily lives allows us to improve our life quality and well-being. New technologies foster a better, more accurate diagnosis and therapy for benign and malignant disease. And there is a new continent that has been developed and creates a new way of communication for mankind. So far there are 12 zodiac signs and seven continents: Asia, Europe, North America, South America, Africa, Australia/Pacific, and Antarctica. Man took possession over most of the land and the sea covering our beautiful planet. Owing to the activities of man, the shape, coloring, and design of our world has changed. As published in European Surgery, Nature, and Science, nature has been largely replaced by science. European Surgery seeks for the myth within nature and science. The natural landscape has been replaced by cultivated environments serving agriculture and the gain of raw materials (oil, gas, ion, etc.). In addition, these raw materials helped us to create and build the eighth continent. Let us name it the digital World Wide Web. The new continent, the eighth continent, the www represents amazing opportunities. Every one of us is used to walking around on this continent. On a daily basis, we spend minutes or hours to discover new aspects of the continent. The continent feeds us with information. As we interact with the eighth continent, we feed the continent with information. Thus, the continuous interaction between us and the eighth continent, i.e., the www, creates an amazing computer science-based digital design, which is going to open new possibilities, hopes, and horizons. But we have to keep in mind that new discoveries share positive and negative qualities, reasons for good and bad climate, storms, winter, summer, and nightmare. We have to be aware that journeys into new subcontinental landscapes may catch us within a digital bub- 


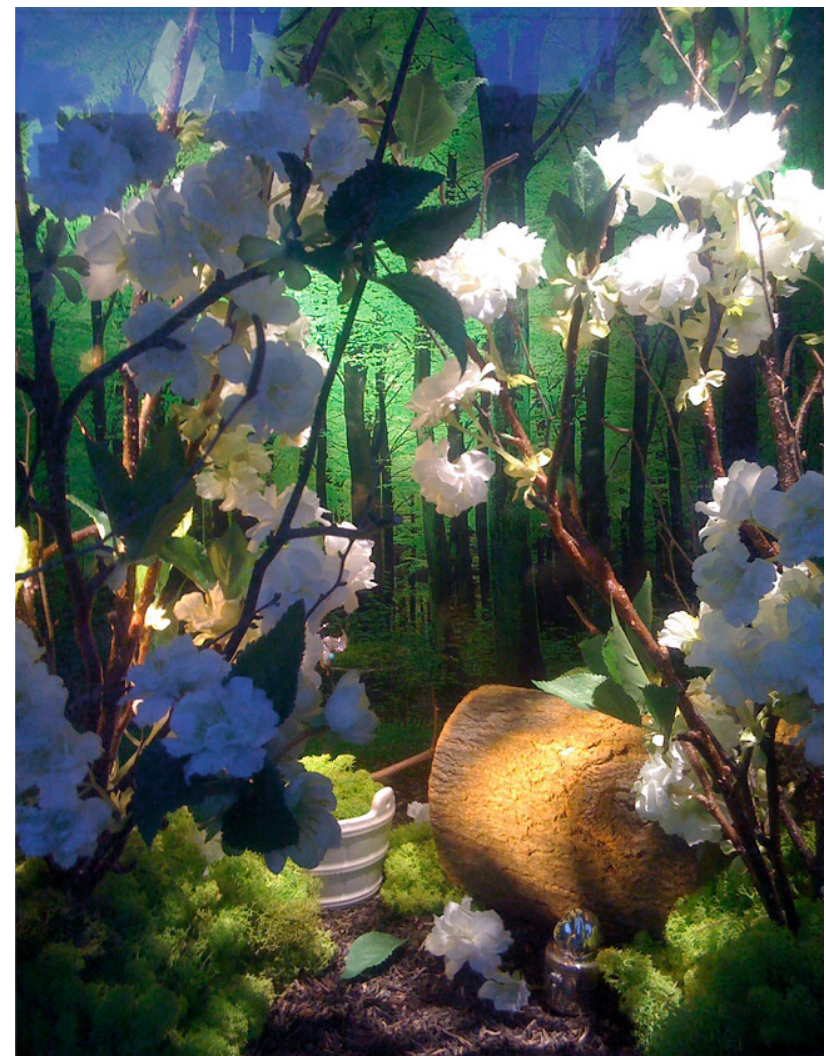

Fig. 1 Image of a paper garden mirrors the author's idea that all our perceptions are of borrowed character and oriented according the individual atmosphere, mood, and temperament of our current existence

ble and alter our behavior, conduct of reasoning, and form of existence. As such, our private and professional life will increasingly be prone and endangered to serve the fascination of the digital technology and industry. In addition, women and men, children and animals become digitally controlled, trained, and designed within the applications of the eighth continent. May the digital technology affect the behavior of our genes and foster the development of a computer technology-based design? May digital intelligence control, prosper, and foster a new form of evolution? May we become the slaves of the robots and the followers of the virtual reality? May robots create a new form of life on planet earth? Thus, it seems highly important to find out how we may learn to outbalance the numerous aspects of the fascinating realities provided by the beauty of the eighth continent. How should we copy and paste emotion and discipline? There exists a large spectrum of possibilities. Hills, valleys, shores, islands, lakes, seas, rivers, mountains, and dessert chains, as beautifully mirrored and depicted within the poetry of Walt Whitman. Go for it, if you find time, Walt created words of dime. How may we learn to select? Find out what is useful? What is valuable for us? What harms our well-being and life quality? When do we start to become the slaves of the involvements of the eighth continent? How may we sense such forms of despotism? Which are the recognizable forms of this despotism? Where do we hide under the moon? Who is going to outline the orientation of stars?

Do you remember your Latin lessons? Gallia omnia divisa est in partes tres......? Since time immemorial, discoveries served to increase political power. As such, open-minded reasoning may ask: "Cui bono?" This question seems to be essential and should be the basis for our conduct of reasoning. The question may stimulate a conduct of reasoning, which contributes to foster an outbalanced approach for our activities within the eighth continent. The advantages of the new continent are well known, described, and presented. Individuals are globally connected, the global village offers amazing possibilities including data processing, sharing, and telemedicine. As such, we as surgeons actively coin the landscape of digital telemedicine for teaching, education, diagnosis, therapy, followup, academic and non-academic medicine, science, trials, and therapy design. Interdisciplinary disease management becomes the order of the day. Rapid decision management fosters successful translation of effective treatment algorithms. Efficacy increases as knowledge widens. Numbers hide, what words cannot tell. The implementation of new discoveries into daily surgical routine allows for the continuous adaptation of modern disease management strategies. Imagination offers novel understanding. As such, robotic surgery enables tailored, highly accurate, and reproducible tissue dissection, tumor resection, and surgical treatment. The eighth continent facilitates the design of treatment algorithms for the patients and the physicians. Increasingly, digital video conference-based consulting is included into the daily communication of physicians and patients. As such, the most time-consuming taking of the patient history will soon be included within the fascinating arms of the eighth continent. Thus, a patient may immediately receive valuable information on how to respond to a given spectrum of complaints including constipation, abdominal discomfort, nausea, vomiting, cough, high blood pressure, headache, migraine etc. Applications included within cell phones, tablets, and laptops allow for universal, global access of medical information and data processing for both the physicians and the patients. It remains to be asked, how much computed, digital communication is capable of replacing the so-called personal conversation. Man to man is so unjust (Bob Marley). As a matter of fact, the large majority of information is easily, well, and adequately taken by the digital platform of the eighth continent. Life is one big road with lots of signs (Bob Marley). And this helps us to gain more time that now can be attributed to the conduct of atmosphere, mood, temperament, and emotion of a given individual (patient, colleague, family member, friend). Patients and surgeons frequently perceive fear, anxiety, sorrow, and insecurity. Who feels it 


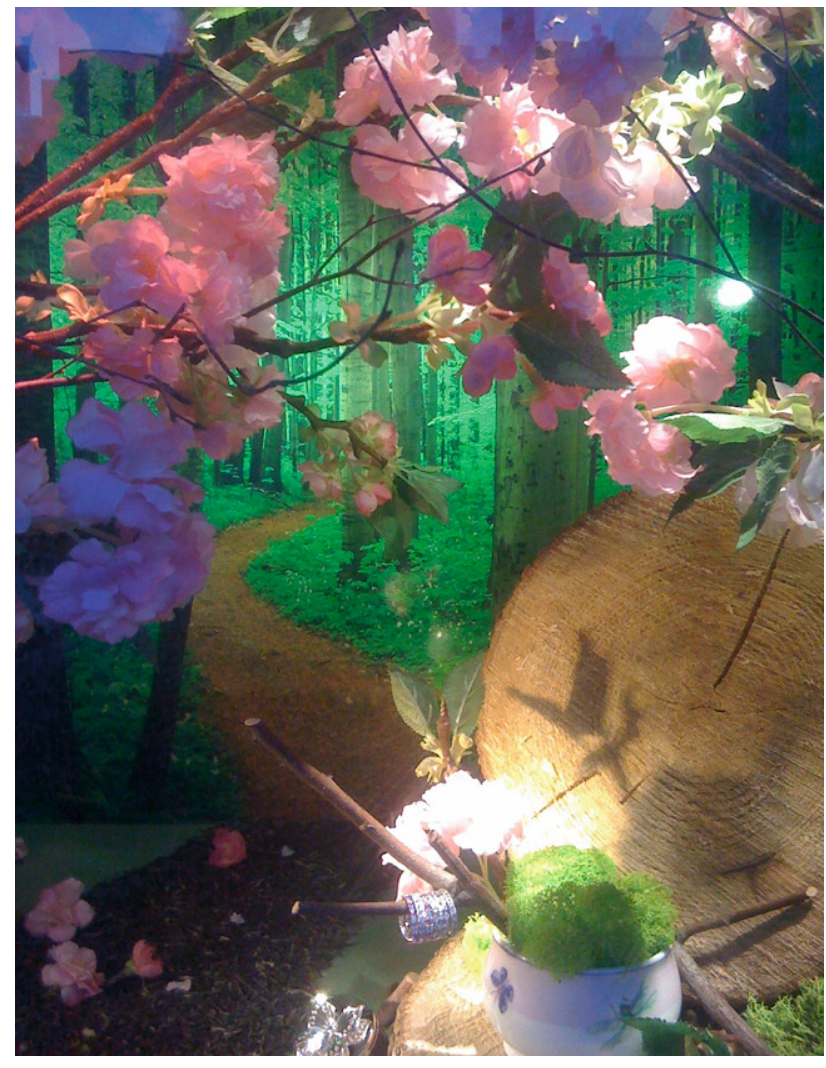

Fig. 2 Image showing another aspect of the paper garden depicted in Fig. 1 mirrors the author's idea that light, focus, and perspective foster the temperament, mood, and atmosphere of our being

knows it. These irritations in turn impair well-being and life quality. Check your e-mail, twitter, social media account. Administer news. Some of these negative emotions may be adequately eliminated or attenuated by digitally mediated and provided short message system information, i.e., "your biopsy demonstrated no evidence of cancer risk" or "your wife does not have cancer" or "the pathological test of the needle biopsy demonstrated inflammation, but there exists no evidence of malignancy" or "your problem needs lifestyle changes" or "your blood pressure is increased and requires a medical therapy, but we will definitely get rid of it" or "do not worry be happy, take it easy." However, there is still place for personal communication and the analogous physical examination. Let us see why, how, and when. The gates are open, the skies widen, and the band of stars is telling the truth. Let us enter the beautiful gardens (Figs. 1 and 2).

Envisioned from the northern hemisphere of our earth planet platform, the milky way-this enormous, gigantic, beautifully, well-spread band of stars (Heraclitus) - extends between the four pillars of heaven: the gate built between the zodiac signs of Scorpio and Sagittarius, and the gate built by the zodiac signs of Taurus and Gemini. These cosmic constellations are of major importance and are thus well represented within the ancient myths of mankind all over the world, within the cultures of all continents (except the Antarctic world) including the eighth continent. Whenever you read about the four pillars of heaven, the two or four gates to the underworld, the columns of Hercules, the columns, gates, pillars to the afterworld and the two front and two rear legs of the cow, the bull, the lion, the sheep, you understand the meaning of these images. These pictures aim to remember and conserve a cosmic knowledge regarding the extension of the Milky Way, which is essential to human mankind for agriculture, orientation, navigation, and reasoning. Through the gates man enters the cosmic clock of the 12 zodiacs. This means, through these gates man enters space time and opens his mind for the valuable information kept for us within the universe. As such, the legacy speaks to us for thousands of years and will, hopefully, for our future. Precession matters. The dancing Shiva counts the dimensions of the small (12 months) and large year (26,000 years). All is one and goes on. As long as we keep the artificial light low, we may be allowed to borrow the beauty of the skies to envision the white-lighted band, where, going in line with the myth of the Cherokee Indians, the dog ran. According to the Cherokee Indians, the dog stole the milk from the mill located within the southern hemisphere of the heavens and crossing the heavens the dog spilled the milk thus creating the milky way. The mill mirrors the precession of the earth, which causes the zodiacs to turn around our skies. As such, the Cherokee myth remembers the same energy as the dynamics of Shiva within the Vedas and Upanishads: space time orchestrates our perception in the form of light, coming in the form of continuously swinging fields and quanta. Reasoning and being is the same (Parmenides).

Digital technology does a lot, but at present empathy, emotion, tune, temper of mood seem to be best taken, sensed, and transmitted within a personal analog communication. "Half day," shouted the group of analog Dublin regulars in Ulysses by James Joyce. Furthermore, "Cesar had a gallico belly," mentioned James Joyce. The physical examination serves to gain essential information including tissue qualities, forms of pain, irritation, and tenderness. Thus, "Them Belly Full, but We Hungry," stated Bob Marley. Nutrition counts dollars of discipline. Maybe in the future, robots will enable us to replace the physician and help us to treat women and men, children, and animals out there on Mars and other future colonies of mankind. Visitors of Mars will usually eat grilled insects, because these small animals are easily reproduced, kept, and stored. Robot surgery demonstrated the benefits, challenges, and advantages of digital medicine, including the transmission of sensory tissue information. Soon these achievements will also translate into robot physician and patient work-up. However, at present we should not be afraid to use the senses of our eyes, ears, fingers, and nose for getting an idea about the sophon, the smell, to reach 
saphon, the wide image required for fruitful diagnosis and therapy of a disease. Let us collect essence for the benefit of mankind and the beauty of our globe. Ideas are the gloves of our being. Light attracts our attention (Figs. 1 and 2). Disease develops behind the light. Think outside the box! Stay tuned to uncover the cause and tank up positive energy for the benefit of your patients.

Sincerely,

Martin Riegler
Acknowledgements The author thanks his parents, sister, wife, families, teachers, and friends for supporting the fruitful delivery of integrity, clarity, and harmony for the orchestration of a different approach toward the qualities of perceptions.

Conflict of interest M. Riegler declares that he has no competing interests. 